\title{
Bio-Tile: An Intelligent Hybrid-Infrastructure
}

\author{
Sara Pezeshk ${ }^{(凶)}$ \\ Florida International University, Miami, USA \\ spezeshk@fiu.edu
}

\begin{abstract}
Bio-tile is a multipurpose artifact designed for protecting the coastline from erosion while creating a landscape element and an architectural experience for visitors. Bio-tile performs as a mitigation strategy to slow down erosion while promoting biodiversity. This paper describes the methodology used to develop the bio-tile as the nexus between digital and environmental for resolving coastline challenges through material tectonics. A non-linear algorithm and nature's inherent code are used to develop the Bio-tile, a nature-based hybrid infrastructure. This approach aims to generate a performance-oriented design by using emergence theory to construct shoreline elements adaptive to climatic conditions.
\end{abstract}

Keywords: Hybrid infrastructure · Formation · Materialization · Construction · Biomimicry $\cdot$ Promoting biodiversity $\cdot$ Performance-oriented design

\section{Introduction}

Coastlines and marine life are under significant climatic pressure due to global climate change and sea-level rise. Erosion and flooding are increasingly destroying marine life in coastal areas, particularly in some coastal habitats such as mangroves and seagrass beds, which remain essential breeding grounds and potential $\mathrm{CO} 2$ capture zones. Some of these concerns are "loss of habitat for numerous marine species and wading birds, further erosion of the property and adjacent properties, water quality degradation, and the interruption of natural shoreline processes."1

In response to coastal problems due to environmental distress, creating "hard infrastructure" is a common and effective technique. This technique involves constructing a concrete or steel barrier along the shoreline to protect against storm surge and wave attack. However, this strategy is causing tremendous harm to our environment increasing the vulnerability of coastal areas to hurricanes and damaging coastal habitat.

As a result, eco-engineers and designers have shifted their efforts to projects that have a minimal impact on the ecosystem while contributing to environmental quality and human experience. One of the more sustainable approaches to respond to this global distress is a nature-based technique to protect the shoreline. This technique, called living or natural infrastructure (green), a common management approach because it is costeffective, preserves biodiversity, and, most importantly, it is resilient. Nevertheless, this

\footnotetext{
${ }^{1}$ Florida Department of Environmental Protection, n.d., para. 4. [2].
} 


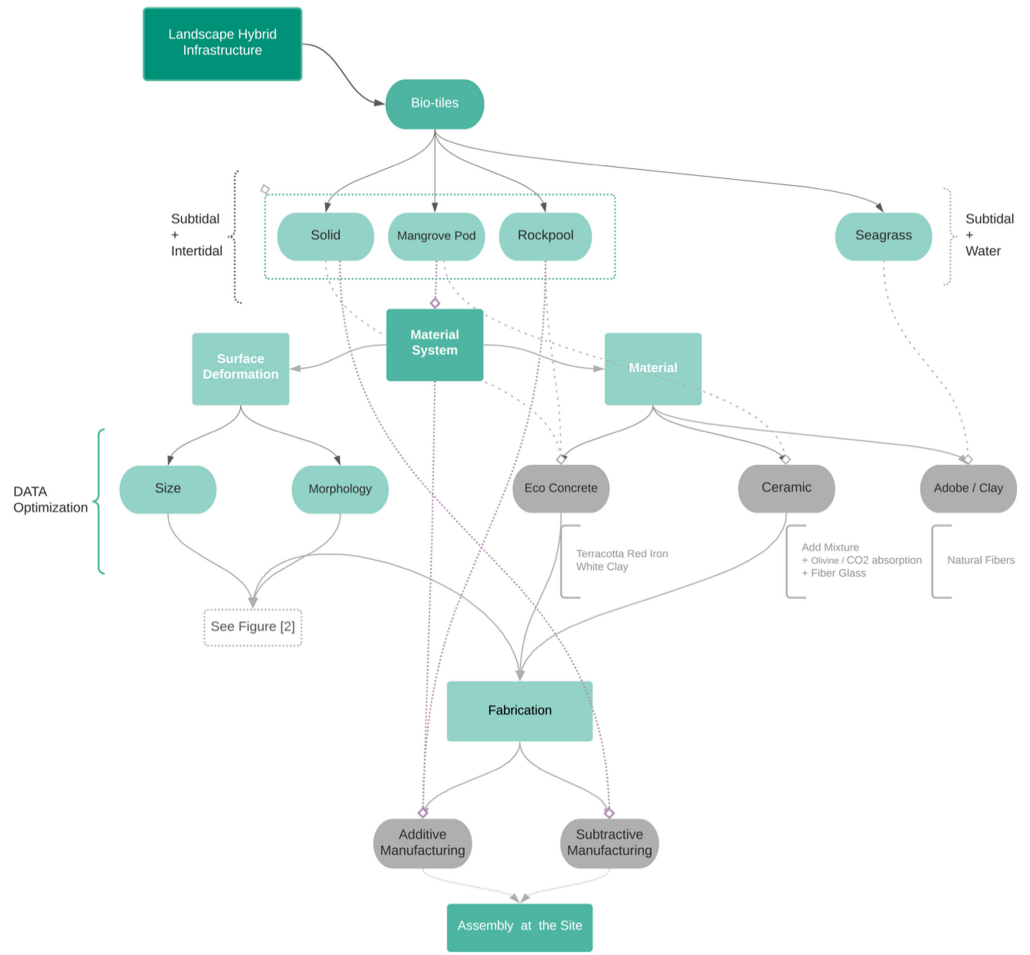

Fig. 1. Morphological design procedure

approach alone is not enough to protect our shoreline due to the high rate of extreme weather events such as storms and hurricanes, and storm surge.

A more innovative approach is a combination of both built (gray) and natural systems (green), called hybrid infrastructure, which is an alternative approach to coastal protection and resilience. ${ }^{2}$ This method is more adaptive and responsive. According to Weinstock, "the emerging architecture that relates pattern and process, form and behavior, with spatial and cultural parameters, has a symbiotic relationship with the natural world."3

In this project, a performance-based material system combined with restored natural green infrastructures, including salt marsh and mangrove is implemented, the project's ambition is to prevent or minimize erosion, maximize biodiversity, and create a healthier environment along the shoreline by designing tiles with bio-enhanced material and surface treatment that host marine organisms (Fig. 1). The creation of process models and simulations and design experimentation that begins with functionality and morphology relationships can be used to investigate new building concepts and geometries. ${ }^{4}$ Bio-tile is a multipurpose living shoreline, designed using a responsive material system

\footnotetext{
${ }^{2}$ Sutton-Grier et al. 2015 [5].

3 Weinstock 27-33 [12].

4 Ibid. [12].
} 
that aims to protect and maintain the natural environment's health and welfare from anthropogenetic harms.

The project focuses primarily on the intelligence of the material system of Biotiles, their configuration, interconnectivity, and evolutionary fabrication process. The Performance-based hybrid infrastructure is generated through a multi-level (micro, macro, and nano levels) simulation process, and four tile typologies that emerge as a result of these process. All four Bio-tile typologies (solid-tile, mangrove pods, rockpool, and seagrass blanket) are responsive to climatic pressures, and each tile has its exclusive performance behavior toward the environment. Simultaneously, all of the tiles promote biodiversity by integrating the material system consisting of material, geometry, and texture deformation (see Fig. 2). Both the Bio-tile configuration and fabrication assembly incorporate self-organization operations within the embedded algorithm, resulting in an optimized arrangement in a specific new territory. According to De Landa, "it refers to the integration of a collection of elements into an assemblage that is more than the sum of its parts, that is, one that displays global properties not possessed by its components."5
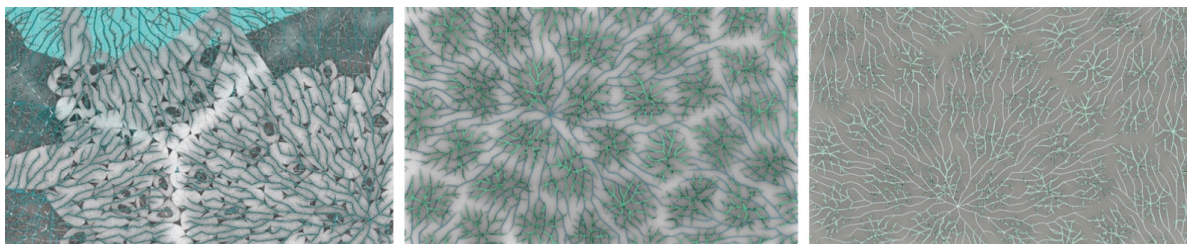

Fig. 2. Rhizomic connectivity

Simultaneously, the multi-performative resilience grounded in the landscape uses a rhizomatic model as fluid networks (roots and water flow) connects all the elements from the coastline to the sea. Rhizomes metaphorically smooth out space and cut through boundaries imposed by hierarchical and orderly vertical lines. Deleuze explained, "Smooth and striated space 'exist only in mixture: smooth space is constantly being translated, transverse into a striated space; striated space is constantly being reversed, returned to a smooth space."6

\section{Design Methodology}

Climate change is inevitable; however, the coastal area is witnessing the first impacts of marine biodiversity loss and the degradation of the ocean ecosystem and its ability to respond to this transition. ${ }^{7}$ Architecture, as a material practice, can demonstrate an alternative solution to this crisis. As Hensel explains, "materials make up our build environment, and their interaction with the dynamics of the environment they are embedded within results in the specific condition we live (Fig. 3). ${ }^{8}$

\footnotetext{
5 DeLanda 20 [20].

6 Deleuze and Guattari 316 [16].

7 http://ocean-climate.org [1].

${ }^{8}$ Hensel et al. [6].
} 


\subsection{Inherent Code of Nature}

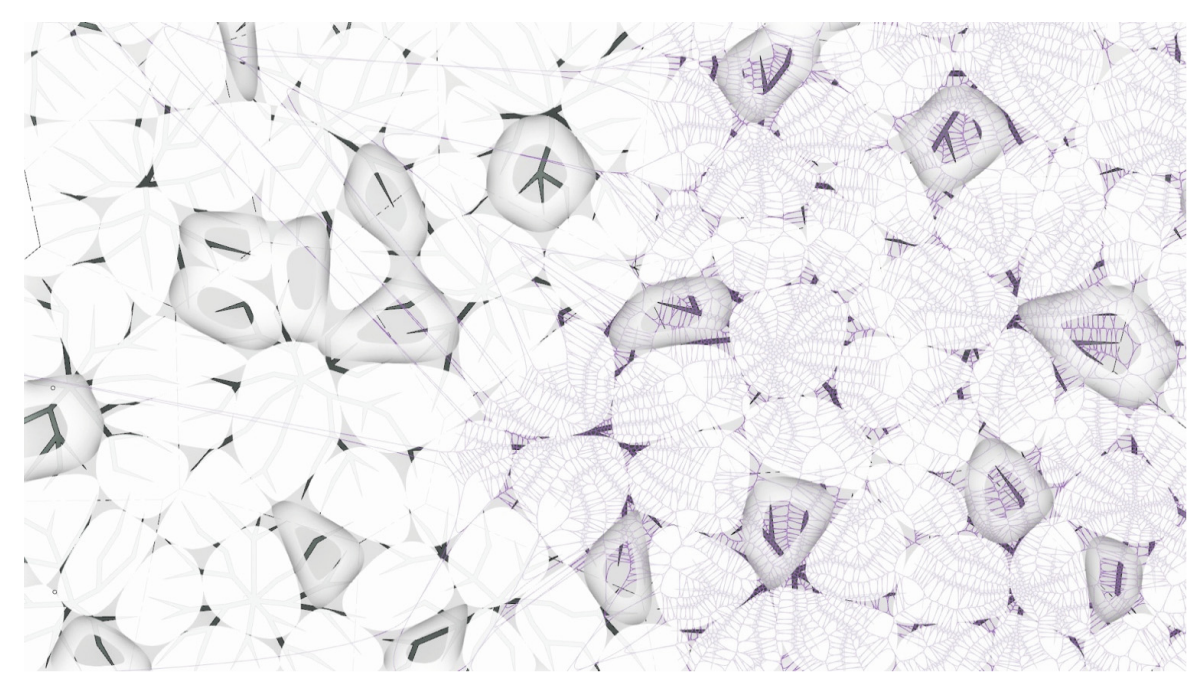

Fig. 3. Bio-tiles configuration rhizomatic connection

According to De Landa, biomimetics is a subfield of materials science that studies biological creatures to extract design concepts applied in a manufacturing setting. He also claims that the intention is not to recreate a material that already exists in nature. ${ }^{9}$ An emergent action constitutes the formation and configuration process in this project. The whole is generated through an equilibrium process. The procedure as an emergent process is not only by the performance behavior and geometrical configuration of these element's relationships at the local scale but also by the performance behavior and geometrical configuration of their relationships at the global scale. According to De Wolf and Holvoet, "Emergence behavior in a complex system occurs as a result of simple interaction among local emergent" when coherent emergent at the macro-level that dynamically arises from the interactions between the parts at the micro-level. As pointed out by Otto, "the geometrically exact forms are rare in nature." 10 As a result, we can only recognize the system behind them by comprehending the phenomenon that causes them. ${ }^{11}$

During the fabrication process, the principle of form-finding is used to construct and configure the Bio-tile formation. Here Material systems manifest as self-organization in these processes, which occur in a far-from-equilibrium model. ${ }^{12}$ Far-from-equilibrium processes are forcing on the foundations of condensed matter and materials physics.

\footnotetext{
9 De Landa [12].

10 Otto and Burkhardt [17].

11 Ibid.

12 De Landa [12].
} 
These materials have structural properties that indicate that they are liquids under equilibrium conditions, but they can act like solids (Fig. 4). ${ }^{13}$

\subsection{Rhizomatic Occupied Territory}
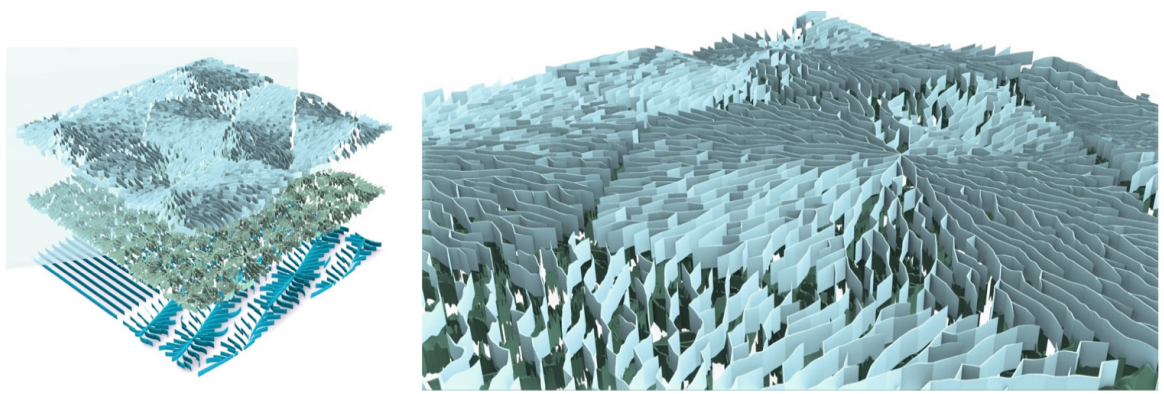

Fig. 4. Rhizomic layering at multi-level

Several ways can be used to connect occupied points, lines, surfaces, and spaces. The surfaces are occupied by living organisms that want or need to interact with one another to live and survive. ${ }^{14}$ The process of occupying the territory at the macro level in this project consists of connecting the elements at the micro level through rhizomatic arrangement, which is made up of many physical lines and invisible links between water flow, mangrove, saltmarsh, and seagrass roots. Deleuze claims that "there are no points or positions in a rhizome, such as those found in a structure, tree, or root. There are only lines." 15 Rhizomes connect the space and cut through boundaries imposed by vertical lines of hierarchies and order. The rhizome achieves the sensation of "becoming" and it creates a correspondence between the self and the other. ${ }^{16}$ Rhizomic connectivity also allows for the flow of energy, which eventually leads to the flow of materials along its paths. Weinstock argues, "the topography of the earth's surface emerges from the interaction of tectonic force that acts on the land from below and the weathering and erosional force that act on it form above." 17 The circulation of energy and material, such as sediment, nutrition, or run-off, follows the sea's shortest path. Otto refers to this as an "invisible path" and states that "transport paths connect the occupied territories. Neither the occupation nor the transport paths have to be material. Often there are no or only the temporary traces." 18

Each Bio-tile module is designated as a space for organisms, plants, or even people congregating together. Even though the final space is referred to as a "space of place"

\footnotetext{
13 Jaeger and Liu [15].

14 Otto and Burkhardt [17].

15 Deleuze and Guattari 8 [16].

16 Leach 90 [10].

17 Weinstock 2010, p. 69.

18 Otto and Burkhardt [17].
} 
it becomes intelligent due to optimal interaction and module combination. The entire system acts and behaves as though it were a set of living organisms wishing to interact with one another. Consequently, "continental flows of energy and material are likely to intensify as intelligent inhabited infrastructure that unites and ecological service systems rather than divide the come on-line." 19

\section{Material-System and the Increase of Biodiversity}

Urban sprawl is widely considered as having one of the most significant impacts on habitat loss and ultimately extinction at local and regional scales. Furthermore, biodiversity loss and depopulation of marine fauna and flora are caused by high water temperatures (which caused bleaching), poor water quality, overfishing, deforestation of mangroves, and erosion. The interaction of formalization and materialization processes centered on material and environment interaction will affect architecture and our human environment by providing a performative setting for human inhabitation. ${ }^{20}$ The relationship between the material system and the environment is a crucial concern in the present climate change context. Any decision we make as architects is critical in avoiding current challenges for future generations. The goal here is to create a material system that develops from interactions between material properties, environmental stimuli, and structural forces (Fig. 5).

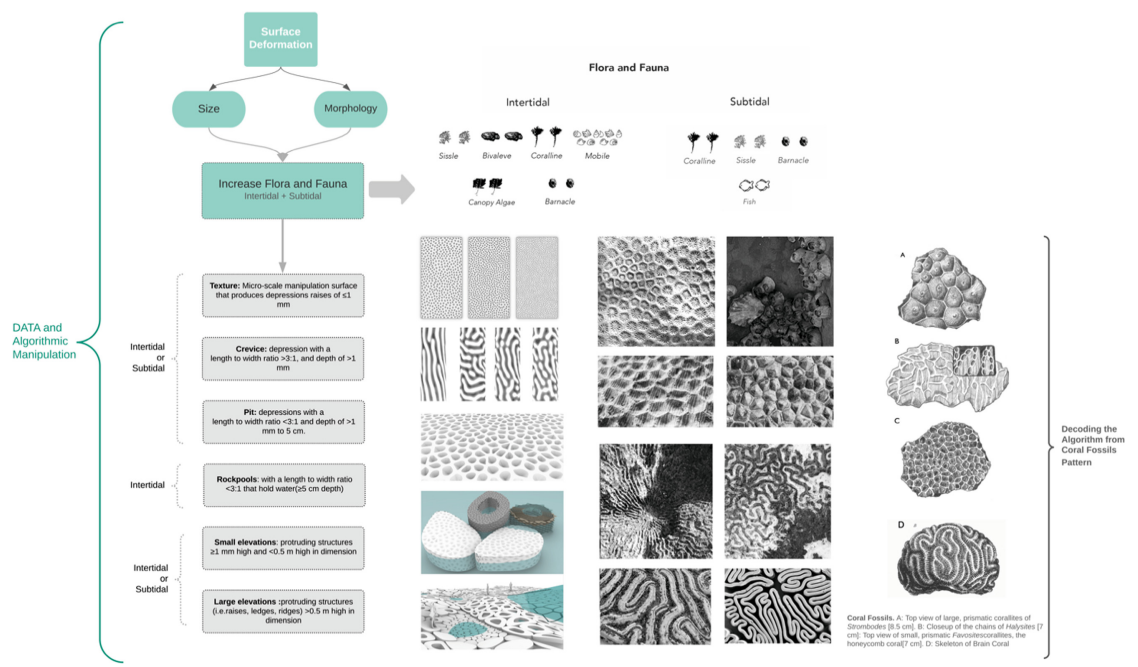

Fig. 5. Morphological design procedure ${ }^{21}$

\footnotetext{
19 Ibid p. 268.

20 Hensel et al. 35-38.

${ }^{21}$ Based on the article, O'Shaughnessy et al. and https://wgnhs.wisc.edu/wisconsin-geology/fos sils-of-wisconsin/coral-gallery/corals/.
} 


\subsection{Ecological Interventions and Surface Manipulation}

Architects use the emergence of mathematics which illustrates our complex natural systems, to create complex forms and effects or intelligent materials and processes for the innovative design of active structures and responsive environments. ${ }^{22}$ Consequently, in this project, I have explored the possibility of creating a surface deformation inspired by the pattern of Fossiliferous limestone, a coral fossil in the local limestone, to create the proposed morphology intervention (Fig. 5). As Zizek describes, the lesson of ecology can extract the rhythms of patterns that are ultimately referenced order and stability. ${ }^{23}$

Increasing texture and surface modulation techniques, according to studies, would increase the abundance of intertidal flora and fauna. In this project, the surface deformation size and morphology are based on a research paper that compares the effectiveness of common eco-engineering approaches and the ecological consequences of adding microhabitats to urban facilities during construction or retrofitting using a quantitative metaanalysis and a qualitative review of 109 studies. The outcomes are catalogues and tables that represent the effect of various interventions such as texture, crevices, pits, subtidal holes, small and high elevations, and soft structures on the abundance of habitat-forming taxa (barnacles, bivalves, branching coralline, canopy algae, and coral). ${ }^{24}$ During the formation process, a textured structure is used to generate the desired surface texture pattern on the concrete. This pattern is based on nature's extracted code to maximize porosity, crevices and holes to create a microhabitat for marine wildlife. Furthermore, the texture morphology provides self-shading in the Bio-tile, which decreases surface temperatures.

\subsection{Material Selection}

Given the scarcity of raw materials and the emissions associated with extracting, manufacturing, and transportation, we as designers must devote more time to seeking out how to use our resources more intelligently to have a lower impact on environmental quality. As Hensel argues, why aren't all materials considered intelligent, given that none are entirely inert in a dynamic environment? Why hasn't material's inherent responsiveness been recognized and exploited ${ }^{25}$

This project aims to restore marine biodiversity to the shoreline by selecting the appropriate material for hybrid infrastructure. As a potential material, bio-enhanced concrete is a form of concrete known as eco-concrete, which minimizes the environment's effect during its production. Today's "neo-concrete" era can provide the opportunity to process the formation more intelligently. Concrete fascinates like no other material because it can be forced into any conceivable mold in its liquid. The concept of new materialism, Leach claims, "that we can open up an inquiry into the non-linear logic and morphogenetic tendencies in the matter and into the capacity of matter to self-organize and play an active role in its formation." ${ }^{26}$ Bio-enhanced concrete minimizes the effect

\footnotetext{
22 Weinstock [12].

23 Zizek [8].

24 O'Shaughnessy et al. [10].

25 Hensel et al. 35-38 [6].

26 Leach 18 [18].
} 

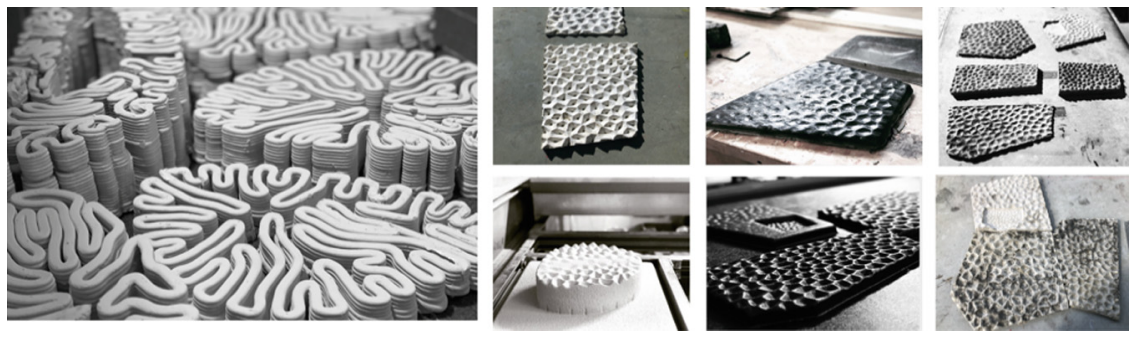

Fig. 6. Material formation of the bio-tile

on the environment during its construction. The enhancement challenge is to reduce the proportion of cement while preserving flowability, processing time, durability, and consistency, thus reducing greenhouse gasses by 30-70 percent. ${ }^{27}$ Also, "Admixtures such as slag sand and pulverized limestone are used to reduce the percentage of Portland cement." 28 Additionally, reinforcements such as fiberglass or carbon fiber have been added to strengthen some of the concrete's limitations, such as corrosion of saltwater, poor tensile stability, and weight. Carbon sequestration is a viable option for reducing pollution. As a low-cost mineral, Olivine is also an excellent candidate to use as a concrete additive since it is widely available and can permanently dispose of $\mathrm{CO} 2$ in an environmentally sustainable and geologically stable way. ${ }^{29}$ The textured bio-enhanced concrete intervention invites microhabitats. At the vertical level and the base, the sea mattress provides more habitat for marine wildlife ${ }^{30}$ moreover, it was ultimately minimizing the ecological footprint (Fig. 6).

\section{Evolutionary Process of Making and Material Formation}

The form generation methodology in this project is based on a bottom-up approach. According to Leach, "The difference, then, lies in the emphasis on form-finding over form-making, on bottom-up over top-down processes", and on formation rather than form. "Formation" itself must in turn be recognized as linked to "information" and "performance" 31 . The assembly technique used in this case is site-specific, and since it is not predetermined, it allows for flexibility and shape variation. (Fig. 7).

The assembly and configuration of the tiles for construction are based on "random occupations," which seem to have no connection concepts at first glance. "However, there tend to be no occupation processes without concepts of regulation," according to Otto, but they are difficult to define. ${ }^{32}$ The strategies of fabrication assembly are simulated through an evolutionary and optimization engine that produces multi-generation configuration. This project's design approaches to address the intersection of digital and environmental

\footnotetext{
27 Knaack et al. [19].

28 Ibid.

29 Béarat et al. 4803 [20].

30 Perkol-Finkel, and Sella [11].

31 Leach 21[18].

32 Otto and Burkhardt [17].
} 

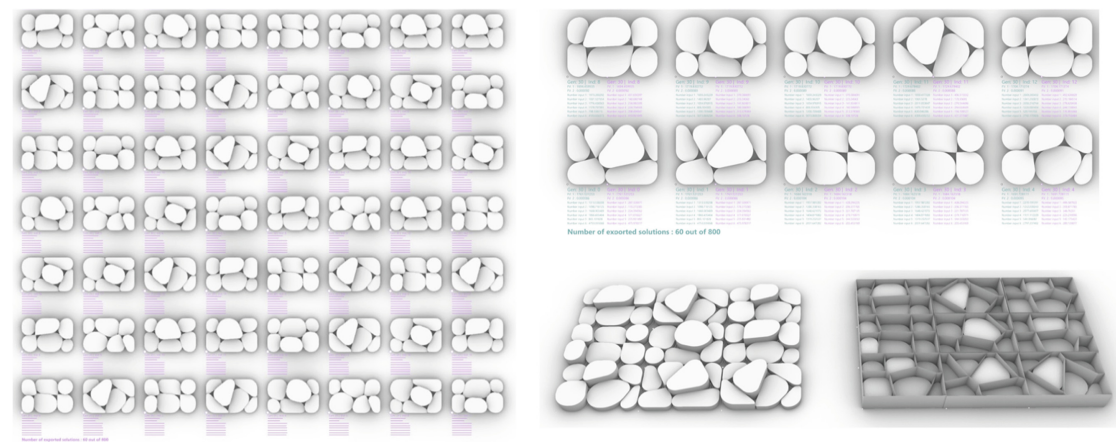

Fig. 7. Evolutionary process using Wallace plugin

problems through informed material tectonics and their connectivity within and across the site. As Picon claims, "It is about how humans are inextricably linked to this dynamic world, and about how materiality, specifically the materiality of architecture, mediates their relationship with it." 33

The fabrication assembly strategies generate multi-generation configurations using an evolutionary and optimization engine. The closed-packed Voronoi formation is generated within a specified multi-fitness objective. The objectives identified in this evolutionary script consist of two critical criteria: 1) the size of the Bio-tile within the 3' by 4' box does not exceed more than $450 \mathrm{sq}$. $\mathrm{ft}$, and 2) the height differentiation to maximize the shadows on neighboring tiles. We used the Wallacie (a rhino plugging) as an evolutionary solver to find the optimal solution and potential configuration (Fig. 8).
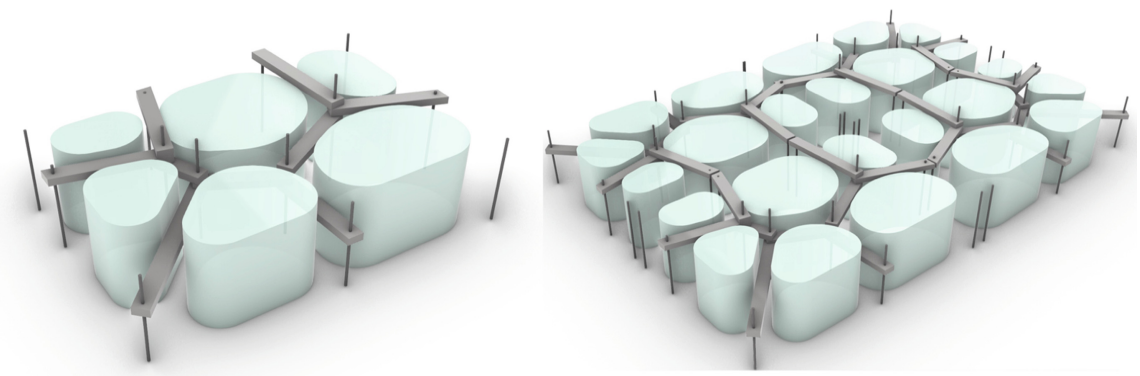

Fig. 8. Form generation technique

As Hensel portrays, "materials enter production and manufacturing processes as raw substances. These strategies are defined by how a material's desired performance is becoming increasingly specific through particular treatment that affects the material." 34 The Bio-tiles are formed in the multiuse and flexible molds using malleable plastic

\footnotetext{
33 Picon [21].

${ }^{34}$ Hensel et al. 35-38 [6].
} 
sheets that are bend into a circular shape formed by a predefined fixed Voronoi boundary framework; this approach is inspired by the experiment minimal path apparatus with soap bubble and "the flexible territory" done by Fei Otto at the Fürleichte Flächentragwerke. Here the process of formation is bottom-up approach and is site-specific, since the method of framework is not fixed and predetermined, it allows for flexibility and shape variations.

\section{Broader Consequences}

Multiple fields and disciplines are needed, all of which must be organized concurrently to create a responsive infrastructure. The sense of understanding the area's ecosystem, the local topographic, surface-water, groundwater, and coastal water hydrology, and geological information of the landscape are all considered concurrently as individual units of the complex. The whole complex is located in the visual space of the structure in a "Becoming" course. As Leach explains, "“Becoming” clearly an interactive process... Becoming always involves reciprocity, a mutual interaction." 35

Now we can ask ourselves if rhizome could be a path especially in relation to transmission, the appropriation and multiplication of our projects by others who participate in it. It's not just networking. It's a "living", open networking. Our architecture builds the conditions of possibility of this rhizome of projects, it is to "make rhizome", "or" it is to go to others, in a perspective of alliance and construction of a collective "becoming" territoriality to share. Because we need to save our planet belonging to every socio-spatial entity and to every living being.

Acknowledgement. This material is based upon work supported by the National Science Foundation under Grant No. HRD-1547798. This NSF grant was awarded to Florida International University as part of the Centers of Research Excellence in Science and Technology (CREST) Program. This project is also part of the Doctorate Project of the DDes Program at Florida International University's Department of Architecture.

\section{References}

1. The Interactions Between Ocean and Climate: (n.d.). Retrieved from 21 April 2020. http:// ocean-climate.org

2. Florida Department of Environmental Protection. Florida Mangrove (2019). https://florid adep.gov/rcp/rcp/content/floridas-mangrovesMangrove

3. National Research Council, Studies, D.E.L., Board, O.S., Coasts, C.M.S.E.A.S., Council, N.R.: Mitigating Shore Erosion Along Sheltered Coasts. Amsterdam University Press, Amsterdam, Netherlands (2007). https://doi.org/10.17226/11764

4. The California Natural Resources Agency, Newkirk, S., Veloz, S., Hayden, M., Battalio, B., Cheng, T.: Toward Natural Shoreline Infrastructure to Manage Coastal Change in California (CCCA4-CNRA-2018-011) (2018). Retrieved from https://www.energy.ca.gov/sites/default/ files/2019-07/Oceans_CCCA4-CNRA-2018-011.pdf

$3 \overline{5 \text { Leach } 83[10] .}$ 
5. Sutton-Grier, A., Wowka, K., Bamford, H.: Future of our coasts: the potential for natural and hybrid infrastructure to enhance the resilience of our coastal communities, economies and ecosystems (2015)

6. Hensel, M., Sunguroglu, D., Menges, A.: Material performance. Arch. Des. 78(2), 34-41 (2008). https://doi.org/10.1002/ad.639

7. De Wolf, T., Holvoet, T.: emergence versus self-organisation: different concepts but promising when combined. In: Brueckner, S.A., Di Marzo Serugendo, G., Karageorgos, A., Nagpal, R. (eds.) ESOA 2004. LNCS (LNAI), vol. 3464, pp. 1-15. Springer, Heidelberg (2005). https:// doi.org/10.1007/11494676_1

8. Zizek, S.: Censorship Today: Violence, or Ecology, a New Opium for the Masses II (n.d.). Retrieved from 5 April 2021. https://www.lacan.com/zizecology2.htm

9. O'Shaughnessy, K.A., et al.: Design catalogue for eco-engineering of coastal artificial structures: a multifunctional approach for stakeholders and end-users. Urban Ecosyst. 23(2), 431-443 (2019). https://doi.org/10.1007/s11252-019-00924-z

10. Leach, N.: "Camouflage." MIT Press, no. 3, MIT Press (2006). https://doi.org/10.1162/leon. 2007.40.3.311

11. Perkol-Finkel, S., Sella, I.: Blue is the new green: eco-engineering for climate change. Marine Technol. Soc. J. 53(4), 7-10 (2019). https://doi.org/10.4031/MTSJ.53.4.13

12. Weinstock, M.: Metabolism and morphology. Arch. Des. 78(2), 26-33 (2008). https://doi. org/10.1002/ad.638

13. De Landa, M. : Matter Matters. Domus Magazine, Issues 884 to 897 (2005). Retrieved from https://www.researchgate.net

14. Mityushev, V.: Pattern formations and optimal packing. Math. Biosci. 274, 12-16 (2016). https://doi.org/10.1016/j.mbs.2016.01.008

15. Jaeger, H.M., Andrea, J.L.: Far-From-Equilibrium Physics: An Overview (2010). http://arxiv. org/abs/1009.4874

16. Deleuze, G., Felix, G.: A Thousand Plateaus. Capitalism and Schizophrenia. Trans. By Brain Massumi. The University of Minnesota Press, Minneapolis (1987).

17. Otto, F., Berthold, B.: Occupying and Connecting: Thoughts on Territories and Spheres of Influence with Particular Reference to Human Settlement, p. 111 (2009)

18. Leach, N.: Matter Matters: A Philosophical Preface. Active Matter (2017)

19. Hildebrand, L., Knaack, U., Hickert, S.: Imagine No. 08: Concretable, p. 22. NAI010, Rotterdam, Netherlands (2015).

20. De Landa, M.: War in the Age of Intelligent Machines. Swerve Editions, New York (1991)

21. Picon, A.: Beyond digital avant-gardes: the materiality of architecture and its impact. Archit. Des. 90(5), 118-125 (2020). https://doi.org/10.1002/ad.2618

22. Béarat, M.: Mineral Carbonation: Role of Passivating Layer Formation. Environ. Sci. Technol. 40(15), 4802-4808 (2006). https://doi.org/10.1021/es0523340 
Open Access This chapter is licensed under the terms of the Creative Commons Attribution 4.0 International License (http://creativecommons.org/licenses/by/4.0/), which permits use, sharing, adaptation, distribution and reproduction in any medium or format, as long as you give appropriate credit to the original author(s) and the source, provide a link to the Creative Commons license and indicate if changes were made.

The images or other third party material in this chapter are included in the chapter's Creative Commons license, unless indicated otherwise in a credit line to the material. If material is not included in the chapter's Creative Commons license and your intended use is not permitted by statutory regulation or exceeds the permitted use, you will need to obtain permission directly from the copyright holder.

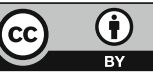

